\section{- Organization of mental illness services: The need for action research}

DEAR SiR

The July Bulletin seems to have been composed round the theme of organization. D. H. Dick (pp. 119-21) provided an excellent and graphic account of some of the problems currently bedevilling management of mental illness services, but failed to explain that little is known about organizing professionals, and that any development has the quality of innovation with all the associated practical and political difficulties.

The next article, by M. Frost and A. Liddell (pp. 121-22), quietly emphasized that psychologists would have to be organized into any comprehensive service. This increases organizational complexity, but seems inevitable given the current trend towards specialization. M. Best (pp. 124-25) offered similar visions from within the profession by suggesting major alteration in psychiatric training, but unfortunately did not spell out the implications for service provision. This seemed to confirm the argument put forward by P. Hill and H. Waters (p. 123) that psychiatrists, especially trainees and junior consultants, show a profound ignorance of, and therefore lack of responsibility for, the profession as a whole and the administrative and planning process within the NHS. Parliament, at least, seems concerned with services and their organization (pp. 125-26). The College also persists in its pursuit of patient protection through a legislated organizational form (pp. 130-32). Dr Freeman's review of 'Maybury' considers public relations (p. 133), and a letter from $\mathrm{Dr}$ Verma (p. 134) asks the question from which organizational solutions must spring: what is the work to be done?

There is undoubtedly an awareness (or at least an awareness of a lack of awareness) about the importance of organization. This encourages me to inform readers very briefly of the work of the Health Services Organization Research Unit at Brunel University. This Unit (HSORU) was set up initially in 1967 by the DHSS and operates by responding to requests for assistance with organization from individuals or groups within the NHS. We have worked a little in the mental illness field in the past ${ }^{1,2}$, but the research method is such that we cannot proceed without an increased determination by the profession to get a grip on its own organizational problems.

As Sir Desmond Pond suggests (p. 118), the re-organization of the NHS provides opportunities for change which may not recur for some time. At present, HSORU has several active projects, including one with a focus on psychiatric services. Our research unit offers the possibility of a systematic collaborative attack on the problems, and we would be interested to hear from anyone who wishes to pursue this path. Our immediate aim is to deal with current issues so as to bring about planned and evaluated change; the long-term research task is the development and testing of concepts and models which might be more widely applicable.
If sufficient interest is about, research conferences can be organized at Brunel University as well.

Psychiatrists already working in well-organized comprehensive services may wish to collaborate with the Unit in a more complex project we are planning. This aims to assist with problems of intersectoral integration: linking psychiatric and other health services, social services, educational services, penal and probation services, employment services, voluntary agencies and private practice.

Brunel University, WARREN KINSTON, MRCPSYCH Middlesex UB8 $3 P H$

\section{REFERENCES}

'Rowbotrom, R. W. \& Bromer, G. (1978) The future of child guidance: A study of multidisciplinary team work. In Health Services, od. E. Jaques. London: Heinemann.

2___ \& HEY, A. (1978) Organisation of Services for the Mentally III. BIOSS Working Paper, Brunel University.

\section{Is dying the province of the psychiatrist?}

\section{DeAR SIR}

Dr Verma (Bulletin, July 1981, p. 134) questions the necessity of a psychiatrist providing support for a research team investigating psychological aspects of the management of terminally ill patients. He also asks whether dying is the province of the psychiatrist at all. These issues are closely related and I would like to deal with them together.

I do not think dying is particularly the province of psychiatrists, but it is a stressful life event and, as such, may precipitate vulnerable people into psychiatric illness. In my experience (over five years, with about two hundred dying patients) most people do have adequate resources to cope with dying. The conditions under which they are most likely to become overwhelmed and break down are:

1. Undue vulnerability to separation and loss, because these experiences have not been successfully worked through in the past;

2. Lack of support from at least one loved and familiar person;

3. Being made aware of their condition at a rate which is inappropriate for them, so that the natural processes of assimilation and adjustment cannot take place.

It is at point number three that the proposed research project could cause undue distress.

In most research interviews the patient knows more than the interviewer and he can choose how much he discloses. He may give away more than he realizes, through non-verbal cues, but at least he feels he controls the amount and rate of disclosure. The dying patient is in an unusual position in that the interviewer may know more about his condition than he does; or at least more than the patient is prepared to admit to himself or others. This means that the questions the interviewer asks or avoids, and his non-verbal cues, may inadvertantly warn the patient about the seriousness of his situation before he is prepared to face it. 
People normally protect themselves from overwhelming psychic pain by the familiar mechanisms of becoming numb at the receipt of totally unexpected catastrophic news, and later by denial and other defences. Thus they pace the entry of this knowledge into awareness, keeping it at a level where they can just cope. Interference with this natural pacing, by unwittingly confronting a patient with information about himself that he is not ready to assimilate, can precipitate undue distress. I have seen this happen when a patient has been upset by an apparently completely tactful interview, by a medical student or trainee (or myself, particularly when 1 was beginning this work). Experience and sensitivity to patients' cues gradually enable an interviewer to learn how to avoid this on most occasions. But the average patient has a wish to know, as well as a wish to deny, and the interview may be the moment when he does find out more, and is temporarily thrown by what he discovers. Recognizing that this has happened, and providing the necessary support, must be part of the equipment of the interviewer. In practice, the interviewer usually leaves the bedside thinking that all has gone well, but a nurse finds the patient in tears an hour or two later. He may not even be able to pinpoint the part of the interview that upset him, but he is likely to refuse to see the interviewer again. Understanding what has happened and helping the patient over this mini-crisis, does require a certain amount of skill, either on the part of the interviewer, if he can get back into the dialogue, or someone else. Appropriately used, the situation can further the patient's adjustment, and he may even by grateful for it later. Badly handled, it leaves an upset, angry patient, and a residue of hostility towards the interviewer, which is usually picked up very quickly by other staff with consequences which could make it harder for the research to continue. I guess the 'Division of Psychiatry' to which your correspondent refers has just this sort of thing in mind when they advocated using a psychiatrist.

But just using a psychiatrist would not necessarily provide an adequate safeguard. Some of us who work regularly in hospices met together recently and we recognized that our basic psychiatric training did not equip us sufficiently to handle the special problems of dying patients. We know that some people without formal training do it very well, because they are sensitive and know intuitively how to respond, as a result of their own life experience. So I sympathize with your correspondent when he asks if dying is the province of the psychiatrist. It is, but only in as much as any other stressful life event which can precipitate psychiatric illness. Even then the psychiatrist is only in a better position than other people to help if he knows how to use his training to the best advantage of the patient. Not all of us do.

AVERIL STEDEPORD Sir Michael Sobell House and Warneford Hospital Oxford.

Dear SiR

Dr Verma (Bulletin, July 1981), asks several questions concerning the role of psychiatrists in the care of the dying. These very issues were recently the subject of a document produced by eight psychiatrists from various countries who took part in the First International Hospice Conference at St Christopher's Hospice during 1980. The resulting document is printed below, and seems to provide a good answer to your correspondent's questions.

C. M. PARKes

St Christopher's Hospice

Lawrie Park Road, SE26

\section{The Role of the Psychiatrist in the Care of the Dying}

1. Hospice and other forms of care of the dying require us to understand the complex inter-relationships of the biological, psychological, social and spiritual needs of patients, families and care-givers.

2. Each group that offers this care must develop its own approaches and must choose the most appropriate staff to meet all of these needs.

3. While recognizing the skills and interests possessed by members of other disciplines who provide counselling and psychosocial support, it is the opinion of the undersigned that the psychiatrist, by reason of training and experience in both medical and behavioural fields, has special skills of value to patients, families and the care-giving team. These include:

(a) Assisting others of the treatment team in the diagnosis and treatment of the organic and functional psychiatric disorders that may accompany the last stages of life of some people (and reassuring others of the normality of their responses to stress).

(b) Working with others of the treatment team to advise on the use of medication and other forms of treatment that may affect behaviour, mood and cognition.

(c) It is the combination of medical and psychodynamic skills which place the psychiatrist in a position to understand and assist with the psychological aspects of life threatening disease for patients and family.

4. We affirm that:

(a) Dying is not psychiatric illness.

(b) The psychiatrists should be a member of the team rather than detached consultants to whom people are passed for treatment.

(c) Psychiatrists must be open to learn from, as well as to instruct, and work with other members of the team of all disciplines.

(d) Psychiatrists should not have sole responsibility for staff support although their special skills in the understanding of psychosocial issues will often enable him to make a useful contribution in this field.

5. We recognize that, at the present time, psychiatrists who have the necessary skills are not always available to those who are pioneering the Hospices and similar units which are developing in so many parts of the world. We regret this fact and recommend that every effort be made to recruit suitable psychiatrists in order to rectify this unsatisfactory situation.

Drs Loma Feigenberg; John E. Fryer; Tetsuo Kashiwag; SAMUEl C. KLAgsbrun; WILLIAM M. LAMERS, JR; EDWIN J. Olsen; Colnn Murray Parkes and Strphin Shanfitld.

[See also Dr Stedeford's account of the conference, p. 189.] 